\title{
As origens conceituais da construção da paz das Nações Unidas*
}

Fernando Cavalcante ${ }^{1}$

\section{Resumo}

A fim de apontar elementos que possam suscitar uma discussão mais aprofundada sobre o entendimento das Nações Unidas sobre o conceito e a prática das suas operações de construção da paz (peacebuilding), este artigo discute a sua formação conceitual. Em vez de abordarmos essas operações como mais um capítulo na "evolução" das operações tradicionais de manutenção da paz (peacekeeping), argumentamos que a origem do conceito de peacebuilding foi resultado da convergência de pelo menos três fatores: o contexto histórico do final dos anos 1980, o ambiente intelectual existente na ONU e sua experiência institucional. Diante da crescente importância assumida por essas operações nas últimas décadas, e da criação de órgãos específicos no seio da ONU para lidar com as questões de peacebuilding, este exercício analítico é fundamental para uma prática mais estruturada por parte da Organização.

Palavras-chave: Construção da paz. Peacebuilding. Operações de paz. Nações Unidas.

\section{Introdução}

Em finais de 2005, foi estabalecida a Comissão de Construção da Paz (CCP) das Nações Unidas (ONU), órgão que seria responsável por coordenar e centralizar o tratamento das questões de peacebuilding no interior da Organização. Con-

\footnotetext{
* Recebido em 24.10.2010

Aprovado em 27.11.2010

1 Doutorando em Política Internacional e Resolução de Conflitos, programa realizado em parceria pela Faculdade de Economia (FEUC) e pelo Centro de Estudos Sociais (CES) da Universidade de Coimbra. Graduou-se em Relações Internacionais pela Universidade de Brasília (2007). Seus interesses de pesquisa e publicação atualmente focam questões de peacekeeping e peacebuilding das Nações Unidas, de teorias das Relações Internacionais e de política externa do Brasil
} 
tudo, qual a origem daquele conceito, seus pressupostos básicos e a que se refere? Ainda, o conceito de peacebuilding a que se refere a CCP é compartilhado pelos demais órgãos e departamentos da ONU? Em que medida?

Com o intuito de lançar alguns elementos que permitam futuramente uma discussão mais aprofundada das questões acima suscitadas, propomos aqui dar um primeiro passo e discutir aquele que foi o primeiro conceito de peacebuilding a entrar no léxico das Nações Unidas em 1992, o de reconstrução pós-conflito (post-conflict peacebuilding). Em outros textos, discutiremos futuramente se e como esse primeiro entendimento de peacebuilding influenciaria o atual entendimento da CCP e da ONU.

Ao invés de abordarmos aqui o conceito de construção da paz como mais um capítulo na "evolução" das operações tradicionais de manutenção da paz ( $p e$ acekeeping), argumentamos que o conceito de reconstrução pós-conflito cunhado no relatório Uma Agenda para a Paz (BOUTROS-GHALI, 1992) foi resultado da convergência de pelo menos três fatores: o contexto histórico do final dos anos 1980, o ambiente intelectual existente nas Nações Unidas e a experiência vivida pelo seu autor - neste caso, a experiência institucional da ONU.

O fim da Guerra Fria, bem como a intensificação do processo de globalização nos finais do século XX, proporcionaram ganhos de ação às Nações Unidas que levaram a mudanças na natureza, no escopo e nos objetivos das tradicionais operações de peacekeeping. Essas mudanças foram acompanhadas pela produção teórica de um vibrante ambiente intelectual que influenciou a ONU, já que havia um clima generalizado de otimismo quanto à possibilidade de que a Organização pudesse assumir um papel mais ativo em questões de paz e segurança internacionais no pós-Guerra Fria. Esse otimismo refletiu-se no mainstreaming dos estudos para a paz, escola de pensamento sobre a paz que cunhou o conceito de peacebuilding ainda na década de 1970, e pela emergência de propostas teóricas que buscavam revisar o próprio conceito de segurança internacional. Tais fatores, aliados à experiência da Organização com os erros e acertos das tradicionais operações de peacekeeping e com a reforma do seu Secretariado, convergiram para proporcionar ao então Secretário-Geral, Boutros Boutros-Ghali a oportunidade de inclui o conceito de reconstrução pós-conflito em seu relatório de 1992. 
Parte da bibliografia de Relações Internacionais especializada em operações de $\mathrm{paz}^{2}$ de fato dá alguma atenção à Agenda para a Paz, identificando as diferenças entre peacekeeping e peacebuilding e enfatizando as mais abrangentes e complexas tarefas desta última (DIEHL, 2008; EHRHART, 2005; FONTOURA, 2009; PARIS; RAMSBOTHAM et al. 2005; SCHNABEL; RATNER, 1995; SISK, 2009). Outros identificam, muito rapidamente, as raízes do peacebuilding nos estudos para a paz ${ }^{3}$, embora sem maiores discussões a respeito da possível influência do conceito da escola dos estudos para a paz naquele primeiro conceito de Boutros-Ghali (BELLAMY et al., 2004; CALL; COOK, 2003; DAVID, 2002; MIALL et al., 1999; PUGH, 1995). Contudo, será aquele entendimento de peacebuilding adotado em 1992 o mesmo a influenciar os trabalhos da recentemente estabelecida CCP? Houve alguma mudança conceitual que viria a influenciar o entendimento atual da ONU? Quais?

No que se segue, espera-se lançar alguns elementos para uma melhor compreensão da forma como a ONU entende e aplica o seu próprio conceito de construção da paz. Na primeira seção, apresentamos rapidamente o conceito de peacebuilding presente no documento Uma Agenda para a Paz e estabelecemos alguns pontos de contato com o conceito dos estudos para a paz. Nesta seção, importância será dada ao ponto de partida do seu entendimento e aos principais objetivos do peacebuilding. Na segunda seção, apresentamos nosso argumento de forma mais detalhada por meio da discussão dos três fatores anteriormente mencionados. Estes são articulados de forma a construir uma proposta de narrativa que demonstre como os três fatores convergiram para o surgimento do conceito de peacebuilding da ONU no início dos anos 1990. Finalmente, na última seção, resgatamos o argumento principal e fazemos algumas considerações sobre esta proposta e suas limitações.

2 Neste texto, e seguindo o uso mais corrente das Nações Unidas, o termo genérico "operações de paz" faz referência às operações de consolidação (peacemaking), manutenção (peacekeeping) e construção da paz (peace-building).

3 Os estudos para a paz (peace studies ou peace research) são aqui entendidos como a escola de pensamento surgida nas décadas de 1950/1960 com o intuito de entender não apenas as causas da guerra, mas também as condições para a paz. Neste sentido, esta escola de pensamento - ou disciplina ou área de estudos - está intimamente relacionada com as idéias que influenciaram a criação dos primeiros centros de pesquisa para a paz nos países nórdicos naquelas décadas. Para referências, DUNN (2005); WIBERG (2005); WALLENSTEEN (1988). 


\section{A definição de peacebuilding no início dos anos 1990}

O termo peacebuilding entrou no vocabulário da ONU em 1992, quando o então Secretário-Geral Boutros Boutros-Ghali lançou um relatório intitulado $A n$ Agenda for Peace: Preventive Diplomacy, Peacemaking and Peace-keeping. No documento, ele definia "post-conflict peacebuilding” (reconstrução pós-conflito) como "[an] action to identify and support structures which will tend to strengthen and solidify peace in order to avoid a relapse into conflict" (BOUTROS-GHALI, 1992, p. 21). Observe o leitor que já neste documento estava presente aquele que viria a ser o aspecto mais característico do conceito de peacebuilding: a idéia de construir a paz, e não apenas mantê-la ou preservá-la, de forma a se evitar a recorrência de novos conflitos após o término de um conflito armado.

A origem acadêmica deste conceito pode ser encontrada na escola dos estudos para a paz, como já mencionado. Embora o termo e sua definição não tenham sido utilizados pela ONU até 1992, é importante destacar que já vinham sendo discutidos desde a década de 1970 por Johan Galtung, considerado um dos fundadores dos estudos para a paz. De fato, não apenas o termo e a definição, mas a própria abordagem tripartida já constava nos escritos de Galtung.

Em seu texto Three Approaches to Peace: Peacekeeping, Peacemaking e Peacebuilding, Galtung buscou encontrar uma síntese entre liberais e marxistas no que diz respeito à idéia de paz. De acordo com o autor, os liberais tendem a enfatizar as estruturas internacionais em seu entendimento de paz, pois argumentam que os Estados podem ser de qualquer tipo, desde que "instituições internacionais igualitárias” possam ser construídas (GALTUNG, 1976, p. 303). Por outro lado, os marxistas argumentam que o "sistema inter-estatal" será capaz de "cuidar de si mesmo" desde que compartilhem do mesmo sistema político - i.e. socialismo. Assim, de acordo com Galtung, os marxistas tenderiam a enfatizar a estrutura intranacional (GALTUNG, p. 303). ${ }^{4}$ Para Galtung, contudo, nenhuma dessas visões poderia, separadamente, levar à paz porque a paz é uma estrutura de vários níveis e que “ $\underline{m u s t}$

\footnotetext{
4 No texto, Galtung não identifica quem são os liberais e os marxistas a que se refere e nem cita textos de referências. Para os propósitos deste artigo, contudo, o mais importante é apreender a sua abordagem da paz como uma estrutura de vários níveis.
} 
be built within nations as well as between nations" (GALTUNG, p. 303) ênfase no original. Ao fazer esta síntese das duas visões, Galtung então conclui que a "peace has a structure, and it is an infrastructure more than a suprastructure (although the two are dialectically related)" ( GALTUNG, p. 303) ênfase no original.

A partir desta rápida apresentação, é possível perceber a centralidade do conceito de paz na proposta de Galtung. A hipótese de que a paz tem uma estrutura, de fato, deriva da sua teoria da violência estrutural, em que os conceitos de "paz" e "violência" são relacionados de tal forma que a paz é entendida como a "ausência de violência" (GALTUNG, 1969). ${ }^{5}$ Assim, Galtung pôde então apresentar uma distinção entre paz negativa - a ausência de violência pessoal ou direta - e a paz positiva - a ausência de violência estrutural (GALTUNG, 1969, 1996, 1981).

É esse arcabouço teórico que orienta as "três abordagens para a paz" do autor. A primeira abordagem é a dissociativa (peacekeeping), que busca manter antagonistas separados - com a ajuda de terceiros se necessário. Um dos principais problemas do peacekeeping, de acordo com Galtung, é que este funciona apenas na minoria dos conflitos armados de sua época: aqueles entre iguais e sem elementos de dominação (GALTUNG, 1976, p. 283-284). A resolução de conflitos (peacemaking) é a segunda abordagem proposta pelo autor, abordagem esta que busca eliminar a própria fonte de tensão, deixando então que o "resto" "tome conta de si mesmo" (GALTUNG, 1976, p. 290). Ainda segundo o autor, esta abordagem é problemática porque se baseia sobremaneira nas "mentes" dos atores, uma vez que a solução para um conflito armado é frequentemente entendida como um acordo já negociado e pronto para ser ratificado pelas partes envolvidas (GALTUNG, 1976, p. 296). Baseado no entendimento de paz como uma estrutura, Galtung apresenta a sua terceira abordagem para a paz, a associativa (peacebuilding). Segundo o autor, esta abordagem busca alcançar a paz a partir da identificação das estruturas " $\underline{\text { that }}$

\footnotetext{
5 Esta conceitualização rompe com o entendimento realista da paz como o oposto da guerra. Para a tradição realista, as relações internacionais são caracterizadas como uma constante luta dos Estados pelo poder, de forma que a guerra seria uma constante e a paz, apenas a sua ausência. Os trabalhos de CARR (2001); MORGENTHAU (2003); WALTZ (1979) estão entre os mais importantes desta tradição.
} 
remove [the] causes of wars and offer alternatives to war in situations where war might occur" (GALTUNG, 1976, p. 298), ênfase no original.

Torna-se então mais fácil de se verificar que tais abordagens gradualmente afastam-se de mecanismos que potencialmente levam a uma situação de paz negativa - a ausência de violência direta - para chegar a mecanismos que levam a situações de paz positiva - também referida como "justiça social” nos trabalhos de Galtung (GALTUNG, 1969). De fato, a abordagem dissociativa, peacekeeping, ao buscar afastar as partes beligerantes, obtém frequentemente como resultado a simples ausência de conflito armado direto entre os antagonistas, i.e. uma situação de paz negativa. Os mecanismos de resolução de conflitos procuram chegar a uma situação que vá além da paz negativa, mas o resultado final é frequentemente muito frágil para ser auto-sustentável e para assegurar que a situação não retorne ao conflito armado. Um dos principais problemas dessa abordagem, de acordo com Galtung, é que os acordos entre os antagonistas são geralmente alcançados por meio da pressão de uma terceira parte no conflito (GALTUNG, 1976, p. 296-297). Do outro lado do espectro, a abordagem associativa, peacebuilding, tem mais chances de proporcionar uma situação de paz positiva, uma vez que sua ação é voltada para “deeper-lying factors in the relation between the parties, in order to arrive at some ideas about how a self-supporting conflict resolution could be found" (GALTUNG, p. 297).

Nesta abordagem, peacebuilding é claramente um mecanismo para se chegar a uma forma de paz sustentável, e não apenas a uma situação de não-guerra. $\mathrm{Na}$ conceitualização do autor, o peacebuilding procura atingir uma paz que não é apenas um dado estado, uma situação temporária de não-guerra, mas sim uma estrutura em si mesma, auto-sustentável. Esta é também o arcabouço conceitual subjacente à Agenda para a Paz de Boutros-Ghali. Contudo, qual o motivo da ausência do conceito de peacebuilding do vocabulário da ONU até 1992? Houve alguma influência dos estudos para a paz na formulação do conceito da ONU? Como? Seguindo a proposta deste ensaio, as respostas a essas questões podem ser encontradas nos diferentes contextos históricos da década de 1970 - profundamente marcado pela marginalização dos estudos para a paz e pela virtual paralisia da ONU - e da década de 1990 - quando os estudos para a paz assumiram a dianteira do pensamento acadêmico sobre a paz e as Nações Unidas vislumbraram 
para si um papel mais ativo nas questões de paz e segurança internacionais. Esta discussão é o foco da próxima seção.

\section{As origens conceituais: uma proposta de narrativa}

Cumpre agora discutir em maior profundidade o aparecimento do conceito de peacebuilding na ONU. Conforme será discutido nesta seção, esse conceito deriva de uma proposta anterior dos estudos para a paz, que se baseava na idéia de atingir uma forma de paz positiva e auto-sustentável. Juntamente com um ambiente intelectual encorajador dentro da ONU, fatores estruturais (contextuais) de finais da década de 1980 e a experiência institucional de quase meio século conduzindo operações de paz convergiram atempadamente e proporcionaram ao então Secretário-Geral o senso de oportunidade para incluir o conceito de peacebuilding em seu relatório.

\subsection{Fatores contextuais: das mudanças no sistema internacional}

Durante os anos da Guerra Fria, as ações relacionadas à área de paz e de segurança internacionais da ONU estiveram virtualmente paralisadas devido à confrontação ideológica entre os Estados Unidos e a União Soviética. O constante uso do poder de veto pelos dois países impediu o funcionamento efetivo do Conselho de Segurança das Nações Unidas (CSNU), o órgão primordialmente responsável por tais questões no interior da Organização. Como alternativa, as Nações Unidas buscaram cumprir suas funções de manutenção da paz e da segurança internacionais por meio das operações de peacekeeping. ${ }^{6}$ Tais operações, que não estavam previstas na Carta da ONU, eram limitadas ao envio de pessoal armado por uma terceira parte no conflito para o exercício de funções tipicamente militares - como a observação de cessar-fogos e armistícios e a manutenção de zonas-tampão. As

\footnotetext{
${ }^{6}$ A United Nations Truce Supervision Organisation (UNTSO, desde 1948) é normalmente referida como a primeira operação de peacekeeping da ONU. Vide GHALI (1993); JAMES (1969, p. 278-290) para referências.
} 
operações de manutenção da paz eram regidas principalmente pelos princípios do consentimento das partes, do não-uso da força e da imparcialidade. ${ }^{7} \mathrm{O}$ escopo dessas operações, portanto, era limitado à simples separação de forças antagnistas - a abordagem dissociativa de Galtung.

Segundo Paris e Sisk (2009, p. 5), pelo menos três razões explicam o limitado escopo daquelas operações durante a Guerra Fria. Em primeiro lugar, a proibição, pela Carta da ONU, da interferência da Organização nos assuntos de natureza doméstica de seus membros (UNITED NATIONS, 1945). As outras razões referem-se ao fato de que ambas as grandes potências não admitiam interferências nas suas respectivas "áreas de influência” e à própria divergência ideológica em relação aos modelos de governança doméstica - democracias liberais versus sociedades socialistas. Tais aspectos também ajudam a entender o reduzido número de operações de peacekeeping estabelecidas após os últimos anos da década de 1970 - período que seria referido como a "década perdida" por Diehl (2008, p. 47-50), uma vez que o CSNU não concordaria com o envio de novas operações para conflitos em curso naquele período. Tais constrangimentos, portanto, enfatizam o caráter das operações de manutenção da paz como primariamente político e pragmático.

O final dos anos 1980, contudo, é marcado pela crescente aproximação entre os Estados Unidos e a União Soviética. Fontoura (2006, p. 84-89) faz um apanhado dessa aproximação em vários momentos, dentre os quais se destacam a publicação de um artigo de Mikhaíl Gorbachev em 1987 e o discurso de George Bush na 44a Sessão da Assembléia Geral da ONU (AGNU), em 1989. Nestas e noutras ocasiões, as duas potências progressivamente mostraram sinais de enfraquecimento da confrontação direta que marcara as décadas anteriores e começaram a enfatizar a necessidade de uma abordagem mais multidisciplinar para as questões de segurança internacional. Em um momento ímpar deste processo, altos oficiais dos dois países escreveram uma carta conjunta ao CSNU comprometendo-se a "to implement and to strengthen the principles and the system of international peace, security and international co-operation laid down in the Charter" (AGNU, 1990, p. 5).

7 Para uma visão geral das operações de paz conduzidas no período da Guerra Fria, vide Diehl (2008); Fontoura (2006); Ramsbotham et al. (2005); Bellamy et al. (2004). 
A crescente reaproximação das duas potências levou ao seu desengajamento das chamadas proxy wars e à consequente redução da assistência econômica e militar que prestavam aos seus aliados, uma vez que perceberam que tais gastos não mais correspondiam aos seus interesses estratégicos. A saída dos Estados Unidos e da União Soviética - posteriormente Federação Russa - desses conflitos criou a oportunidade que as Nações Unidas esperavam para cumprir mais eficazmente com a sua responsabilidade de manutenção da paz e da segurança internacionais. Além da oportunidade, a Organização apresentava-se também mais propensa e capacitada a assumir este papel porque o uso do poder de veto no CSNU passara a ser menos frequente. ${ }^{8}$

Ademais, as atitudes dos EUA e da URSS em relação à ONU contribuíram para criar a impressão de que finalmente "the world body would fulfil its ambitious 1945 founding goals” (BURGESS, 2001, p. 1). De um lado, a União Soviética reconhecia, pela primeira vez, que o papel do Secretário-Geral não era apenas de natureza administrativa, mas também política. De outro lado, como antigo representante dos EUA na ONU, o recentemente eleito Presidente George Bush buscou estabelecer uma parceria efetiva com a Organização, o que começou com a sua vontade para negociar o deficit orçamentário do seu país junto à ONU (THANT; SCOTT, 2007).

Concomitantemente à reaproximação entre as duas potências, o processo de globalização de finais do século XX também teve uma forte influência no surgimento do peacebuilding da ONU. ${ }^{9}$ Em uma crítica à falta de estudos que buscassem estabelecer os mecanismos causais associando o fim da Guerra Fria às mudanças sofridas pelas operações de paz nos anos 1990, Jakobsen argumenta que a globalização provê o "elo perdido" entre os dois processos. Segundo o autor, a "vitória" do Ocidente em 1989 influenciou o processo de globalização de um modo muito particular, facilitando o "spread of the Western model of governance characterized by market economy, democracy and human rights to the rest of the world" (JAKOBSEN, 2002, p. 268). Três aspectos em especial, ele argumenta, causaram a dissemina-

8 Entre 1990 e 2003, o poder de veto foi invocado apenas doze vezes, em contraste com as 193 utilizações entre 1945 e 1990 (WEISS, 2003, p. 150).

9 O processo de globalização é aqui entendido segundo os termos mais amplos de Held et. al. (1999), e não apenas em termos econômicos. 
ção desses valores: a introdução de condicionalidades econômicas e políticas nos programas de desenvolvimento e assistência dos países do Ocidente, a mudança normativa que tornou possível o estabelecimento de operações de paz em apoio aos direitos humanos e à democracia, e a mais intensa cobertura midiática das violações dos direitos humanos (JAKOBSEN, 2002, p. 268).

Nesse sentido, parece-nos factível argumentar que a realidade internacional pós-1989 foi definida principalmente pelos “vencedores” da Guerra Fria, que ditaram os termos de uma ordem global fortemente marcada por valores Ocidentais como a democracia liberal e a economia de mercado, além de normas que legitimavam o uso de operações de paz como recursos para a continuidade e a expansão da própria ordem. ${ }^{10}$ Neste contexto, e com a ONU mais apta a atuar, o conceito de peacebuilding poderia finalmente tornar-se relevante dentre os seus instrumentos de resposta a situações de conflitos armados.

Esses dois fatores - o fim da Guerra Fria e a aceleração do processo de globalização - trouxeram ganhos de ação às Nações Unidas no campo de paz e segurança internacionais. A Organização ganhou força como estabilizadora das relações entre os Estados principalmente porque conseguiu espaço político para atuar, a partir da década de 1990, nas áreas de conflito em que os Estados Unidos e a União Soviética não atuaram (ou não quiseram atuar) diretamente nas últimas décadas - inclusive em conflitos intra-estatais. Além disso, a disseminação de valores Ocidentais - especialmente quando camuflados por discursos de pretensa universalidade - serviu para legitimar a atuação da ONU. Em consequência, a Organização passou a dispensar maiores recursos, tanto políticos quanto financeiros, para a concretização de suas operações. Esses esforços tornam-se particularmente evidentes se considerarmos o aumento no número de operações estabelecidas no período $^{11}$ e nas mais ambiciosas e complexas tarefas que a ONU passou a conduzir - algumas dessas tarefas, como a supervisão e o monitoramento de eleições e a

\footnotetext{
${ }^{10}$ Este ponto é aprofundado na próxima seção.

${ }^{11}$ Entre 1945 e 1987, a ONU estabeleceu 14 operações de paz, enquanto 20 operações foram estabelecidas entre 1988 e 1993. Um outro indicador é o aumento do orçamento da Organização para as operações de paz, que saltou de US\$ 230 milhões em 1988 para US\$ 3,61 bilhões em 1993 (BURGESS, 2001, p. 5).
} 
reconstrução do aparato estatal, eram até então raramente conduzidas em âmbito das operações de peacekeeping. ${ }^{12}$

\section{0 ambiente intelectual: da marginalização ao mainstream}

O contexto emergente com a queda do muro de Berlim alterou drasticamente a concepção "tradicional" de segurança internacional, até então entendida principalmente como o uso da força militar contra agressões externas diretas, normalmente de outros países. O novo entendimento de segurança internacional, que incorporou "novos atores" e "novas ameaças", serviram como um discurso para legitimar e guiar as ações da ONU nos anos imediatamente posteriores ao fim da Guerra Fria. Neste sentido, o ambiente intelectual em que tal concepção surge abriu espaço para que a Organização resgatasse as formulações teóricas da escola dos estudos para a paz e as utilizasse para fundamentar o seu recentemente criado conceito de peacebuilding.

No início dos anos 1990, quando o término da Guerra Fria parecia implicar o fim dos conflitos armados entre estados na arena internacional, houve um aumento no número de conflitos no interior desses estados (WALLENSTEEN; AXELL, 1994). Nestes conflitos, a violência era frequentemente perpetrada por agentes não-estatais - como grupos rebeldes e milícias - e por meios não-oficiais - como a guerra de guerrilha. Tais eventos levaram alguns estudiosos a repensarem os cânones clausewitzianos da guerra, que eram primariamente baseadas no paradigma da violência entre Estados (VAN CREVELD, 1991). Nos anos 1990, portanto, "novos atores" e "novas" formas de guerra foram incorporados ao nível do internacional. ${ }^{13}$ Ademais, enquanto Robert Jackson (1990) "descobria" que muitos dos Estados do chamado Terceiro Mundo careciam de alguns dos atributos distintivos de um Estado soberano - estes eram, portanto, apenas "quase-Estados"

12 Algumas dessas funções haviam sido desempenhadas apenas pelas operações no Congo (ONUC, 1960-64) e na Nova Guiné (UNSF, 1962-63), (PARIS, 2004).

${ }^{13}$ A percepção dessa nova conflitualidade levou a uma série de estudos que, no final daquela década, culminaria com o conceito de "novas guerras" (KALDOR, 1999). 
- a instabilidade doméstica das regiões periféricas foram também incorporadas à lista das ameaças à segurança internacional. ${ }^{14}$

Em um quadro fortemente marcado pela intensificação do processo de globalização (conforme discutido na seção anterior), o alcance desses riscos e ameaças foi percebido como global. Ao mesmo tempo, a resposta dos estados passou por um processo de regionalização que levou à criação de novos ou reforçou mecanismos já existentes de consulta e coordenação internacional nesse campo, como a União Européia Ocidental (WEU) ou a Organização dos Estados Americanos (OEA). Tal processo representou uma mudança em relação às atitudes que prevaleciam no período da Guerra Fria e refletiu "a strong perception that, in an interconnected world order, effective security cannot be achieved merely through unilateral action. Rather, national and international security are considered in some degree indivisible" (HELD et al., 1999, p. 126). O "tradicional" conceito de segurança era então simultaneamente alargado para incluir ameaças além da esfera dos Estados - como a segurança econômica ou ambiental (BUZAN, 1991; HOMER-DIXON, 1991) - e aprofundado, incorporando sujeitos de segurança ao lado do estado como os próprios indivíduos viriam a ser na conceitualização de segurança humana (PNUD, 1994). ${ }^{15}$

Em âmbito das Nações Unidas, a Agenda para a Paz representa o grande marco dessa mudança conceitual. No documento, Boutros-Ghali identificava riscos à estabilidade global que não estavam mais restritos ao plano internacional - como o racismo ou a degradação ambiental (BOUTROS-GHALI, 1992, p. 12-13). Tais riscos foram então incorporados ao conceito de segurança internacional da própria ONU. Ao fazê-lo, a Organização reconhecia a limitação das suas operações de peacekeeping: estas eram restritas à manutenção da paz e suas ações buscavam atender a anseios de um único ator, o Estado. Fazia-se, portan-

\footnotetext{
${ }^{14}$ Ao longo dos anos 1990, emergiria uma vasta bibliografia sobre esses estados, fossem eles "falhados", "falidos", “colapsados", "frágeis" ou "fracos". Para referências, Zartman (1995); Rotberg (2002); para uma revisão, Pureza et al. (2006).

${ }^{15}$ Essas discussões seriam aprofundadas no decorrer dos anos $1990 \mathrm{com}$ debates em torno do "novo" humanitarismo e, já nos anos 2000, da "responsabilidade de proteger". Vide, e.g., Evans (2008).
} 
to, necessário adaptar e legitimar as ações da ONU para os "novos" conflitos domésticos, desde que fossem caracterizados como ameaças à paz e à segurança internacionais pelo CSNU.

Como uma tentativa de solucionar essa limitação, o documento sistematizava e definia todo o escopo da atuação da ONU em questões de segurança em termos de quatro áreas: preventive diplomacy, peacemaking, peacekeeping e post-conflict peacebuilding. Tais áreas refletiam um entendimento dos conflitos armados em termos de fases e seriam aplicados da mesma forma: "preventive diplomacy seeks to resolve disputes before violence breaks out"; peacemaking e peacekeeping, após a cessação das hostilidades; e post-conflict peacebuilding, após a "terminação" do conflito armado (BOUTROS-GHALI, 1992, p. 21). Assim como na proposta de Galtung, muito além de simplesmente conter as hostilidades entre as partes beligerantes (abordagem dissociativa, peacekeeping), Boutros-Ghali reconhecia a necessidade de edificar a paz e prevenir o ressurgimento dos conflitos armados por meio da abordagem associativa (peacebuilding).

Não apenas os termos e a estrutura geral, mas também os conceitos subjacentes à Agenda para a Paz parecem seguir a proposta de Galtung de 1976. O documento é baseado em sua distinção de paz negativa - a ausência de violência direta, e portanto de danos físicos - e de paz positiva - a ausência das formas estruturais de violência que previnem o bem-estar físico e social dos indivíduos (GALTUNG, 1969). Neste sentido, o estabelecimento de operações de paz a partir de então representaria uma mudança do objetivo de atingir uma paz negativa - por meio de mecanismos de peacekeeping que controlassem a violência direta - para uma paz positiva, que deveria ser construída pelas mais ambiciosas operações de peacebuilding. Embora não fosse mencionada na Agenda para a Paz, a abordagem de Galtung representa a paz e a segurança como conceitos "holísticos, multidimensionais e indivisíveis" (TERRIFF et al., 1999, p. 73), que passariam a estar refletidos no conceito e na prática da Organização em questões de paz e segurança internacionais a partir dos anos 1990. De fato, esses seriam os objetivos da maioria das operações de paz estabelecidas pela ONU após 1989, quando a UNTAG foi enviada para a Namíbia (DIEHL, 2008; PARIS, 2004; BELLAMY et al., 2004). 
A renovação da abordagem onusiana de paz demonstra uma forte inspiração tanto na produção intelectual quanto na postura dos estudos para a paz, que deixava então a marginalidade dos anos 1960-70 e assumia um papel mais central entre acadêmicos e formuladores de políticas nos anos 1990 (PUREZA, 2008; WIBERG, 2005; DUNN, 2005, p. 41-64). Quando Galtung publicou as suas "três abordagens para a paz", os estudos para a paz estavam atravessando o que Wiberg se referiu como a sua "primeira crise". ${ }^{16}$ Em debates acerca das posições epistemológicas e acerca do que deveria ser considerado legítimo dentro do seu campo de estudos, proponentes de uma "nova agenda" defendiam a análise de questões como a dinâmica da exploração e dominação em oposição à "velha agenda" dedicada ao estudo das causas da guerra e da dinâmica das armas (WIBERG, 2005, p. 24). Esta crise seria crucial para a consolidação dos estudos para a paz como uma reação ao tipo de pesquisa "tradicionalmente" realizada em Relações Internacionais - cujo principal objetivo era a maximização dos interesses dos governos nacionais ( $\mathrm{SCH}$ MID, 1968, p. 218-219) - e para o fortalecimento da identidade crítica dos estudos para a paz.

No contexto de mudanças internacionais na década de 1990 e diante da proliferação de novas construções intelectuais, Boutros-Ghali conseguiu inserir o conceito de peacebuilding em seu documento de 1992. As mudanças no conceito de segurança internacional, bem como o resgate de importantes formulações teóricas dos estudos para a paz, portanto, tiveram importância fundamental na elaboração do conceito de peacebuilding das Nações Unidas no início dos anos 1990.

\section{A experiência institucional das Nações Unidas}

Como anteriormente discutido, a ONU fortaleceu-se, após o fim da Guerra Fria, como estabilizadora das relações entre Estados. Como reflexo, as tradicionais operações de peacekeeping da Organização cresceram a um ritmo sem preceden-

\footnotetext{
${ }^{16} \mathrm{O}$ autor identifica duas outras crises: uma segunda nos anos 1980, relacionada à agenda excessivamente ampla dos estudos para a paz, e uma terceira crise nos anos 1990, relacionada à idéia de transcender a Guerra Fria.
} 
tes e adquiriram funções inimagináveis durante as anteriores décadas de virtual paralisia do Conselho de Segurança. A fim de responder às expectativas dos seus membros quanto a essas novas ações, portanto, a Organização precisava aprimorar sua capacidade de conduzir tais operações de paz. Neste sentido, a experiência de quase cinquenta anos à frente dessas ações levou a ONU a concretizar duas importantes medidas nos primeiros anos da década de 1990: a reestruturação do seu Secretariado-Geral e a reconsideração dos três princípios até então considerados fundamentais para o estabelecimento de uma operação de manutenção da paz.

Até 1992, as funções relacionadas às operações de paz eram conduzidas em caráter ad hoc pelo Secretário-Geral ou pelos chamados "Sub-Secretários sem Portfólio" e, após 1961, pelo Escritório para Assuntos Políticos Especiais (BELLAMY et al., 2004, p. 48-50). Assim, o planejamento, a conduta e mesmo as ações de inteligência das operações de paz das Nações Unidas não estavam sob a autoridade formal de nenhum departamento ou estrutura institucional dentro do sistema ONU, mas frequentemente de indivíduos, como ilustra o envolvimento de Dag Hammarskjöld na operação enviada à República Democrática do Congo nos anos 1960 (DURCH, 1993b). Este modelo de funcionamento parecia funcionar relativamente bem até o final dos anos 1980, quando o aumento no número de operações de paz sobrecarregou o pequeno número de funcionários dedicados a essas questões. De acordo com Durch, as consequências foram demandas concorrentes aos funcionários, interrupções no planejamento de algumas operações e a falta de comunicação efetiva entre Nova Iorque e as operações no terreno (DURCH, 1993a, p. 60). Ademais, os problemas de coordenação tornaram-se evidentes, por exemplo, durante a operação da ONU no Cambodja, quando as divisões civis e militares da operação da ONU "conducted separated missions surveys and developed distinct mission plans before they were deployed" (BELLAMY et al., 2004, p. 49).

A criação do DPKO não foi apenas uma medida administrativa, mas refletiu também as reformas mais amplas propostas por Boutros-Ghali nas questões de paz e segurança. O novo Departamento replicou a própria concepção teórico-filosófica e a prática das operações de paz após o fim da Guerra Fria, que eram pautadas por objetivos mais amplos e complexos e por ações mais concretas. De fato, o estabelecimento do DPKO teve um forte impacto na expansão dos mandatos das opera- 
ções recém-criadas, a começar porque o Departamento tinha mais pessoal que o antigo Escritório para Assuntos Políticos Especiais. Com a nova estrutura, especial atenção poderia ser dada à reformulação das ações militares e às "novas" actividades nos domínios político, humanitário, social e econômico. Tais atividades foram um aspecto essencial nos mandatos das operações criadas na época e refletiam o mais amplo objetivo de construir, e não apenas de manter a paz.

Concomitantemente a essas mudanças administrativas, os "novos" cenários para os quais era agora chamada a atuar levou a ONU a repensar a necessidade e eficácia dos três princípios até então considerados fundamentais para o estabelecimento de uma operação de manutenção da paz. Assim, a chamada "trindade sagrada" composta pelo consentimento das partes, especialmente o país que acolheria a operação; a restrição do uso da força pelas forças de paz, exceto nos casos de legítima defesa; e a imparcialidade em relação ao conflito, i.e. os peacekeepers deveriam ser vistos como neutros no conflito pela população do país de acolhimento (DIEHL, 2008, p. 6-7; FONTOURA, 2006, p. 87-98; BELLAMY et al., 2004, p. 95-101; RATNER, 1995, p. 26-41, 51-54). Tais princípios estavam presentes na esmagadora maioria das operações de paz realizadas até o final da Guerra Fria.

As novas realidades para as quais as operações de paz foram estabelecidas a partir da década de 1990, no entanto, requeriam alguma flexibilidade daqueles princípios. Com efeito, nas operações realizadas a partir dos anos 1990, a ONU passou a atuar frequentemente em situações de conflitos intra-estatais, onde as autoridades no poder geralmente não eram reconhecidas pelas outras partes no conflito, que também se julgavam legítimas para consentir ou não a implantação de uma operação de paz. No que diz respeito à imparcialidade, as novas ações com o objetivo de conduzir eleições ou apoiar governos de transição geralmente implicavam que a ONU tinha que favorecer alguma das partes envolvidas, evitando assim o rígido entendimento de imparcialidade que prevalecera durante a Guerra Fria. Finalmente, o uso da força pelos peacekeepers da ONU foi flexibilizado porque as novas ações exigiam mais que o uso de "armas leves", uma vez que algumas das tarefas autorizadas durante a década de 1990, tais como a protecção de civis, exigia maior força militar. Segundo Diehl, portanto, "although peace operations have not 
abandoned the original three principles, there is now considerably more variation along the three dimensions than ever before" (DIEHL, 2008, p. 58).

Em suma, tanto a criação do DPKO quanto a revisão dos princípios "tradicionais" de peacekeeping permitiram à Organização aperfeiçoar ou modificar os procedimentos anteriormente adotados na condução desses operações. Tais modificações foram então consideradas e implementadas nas mais recentes operações de peacebuilding, que, a partir dos anos 1990, seriam aquelas mais frequentemente estabelecidas pela ONU.

\section{Considerações finais}

Dentro do espectro de operações de paz da ONU, as de peacebuilding se tornaram as de maior destaque após o fim da Guerra Fria, principalmente devido à grande variedade de atividades que realizam e aos seus objectivos mais amplos de construir a paz - e não apenas mantê-la, como faziam as operações de peacekeeping. Contudo, é este mesmo conceito do início dos anos 1990 que oriente hoje a prática da ONU? A criação da Comissão para a Construção da Paz em finais de 2005 trouxe mudanças para este conceito e para as ações concretas nele baseadas? As respostas para estas questões têm relevância não apenas por elucidar o entendimento da própria ONU em relação ao conceito e à prática do peacebuilding, como também por apontar como o conceito ganhou, progressivamente, destaque no rol das respostas da Organização a situações de conflitos armados.

Neste artigo, buscamos contribuir para essa discussão ao apontar elementos que possam suscitar respostas mais aprofundadas sobre as questões acima. Tal contribuição foi aqui realizada por meio da análise da gestação do conceito de peacebuilding das Nações Unidas como definido no documento Uma Agenda para a Paz, de 1992. Para este efeito, buscamos aqui adotar uma postura analítica que considerasse tanto aspectos materiais quanto ideacionais para a análise do peacebuilding. Argumentamos, assim, que aquele primeiro conceito de peacebuilding da ONU foi influenciado por pelo menos três fatores, intrinsecamente relacionados entre si e que se influenciam mutuamente: o contexto histórico marcado pelo fim 
da Guerra Fria e pela intensificação da do processo de globalização; o ambiente intelectual que possibilitou o surgimento de um entendimento renovado sobre a segurança internacional; e a longa experiência institucional da ONU na condução de operações de paz.

A análise aqui realizada não é, obviamente, a única possível, mas é apenas uma interpretação, uma forma de conferir coerência à gestação do conceito de peacebuilding da ONU no início dos anos 1990. Esta análise deve ser entendida como um esforço no sentido de explorar questões conceituais subjacentes às operações de paz da ONU, aspectos que só tardiamente receberam a atenção adequada dos estudiosos da área das Relações Internacionais. Neste sentido, e considerando-se a recente criação da CCP no seio da ONU, cumpre discutirmos como este conceito foi entendido e modificado pela Organização ao longo dos últimos 20 anos, aproximadamente. Em contribuições futuras, pretendemos analisar como essas mudanças ocorreram, também na ONU, nos níveis teórico, operacional e institucional.

\section{The conceptual origins of United Nations peacebuilding}

\section{Abstract}

In order to point out elements that may support further discussions on the United Nations concept and practice of peacebuilding, this paper discusses its very conceptual formation. Instead of addressing peacebuilding as another chapter in the ?evolution? of traditional peacekeeping operations, it is argued that the origins of the peacebuilding concept was a result of the convergence of at least three factors: the historical context of late 1980, the intellectual environment at the UN and the Organization? institutional experience. Given the increasing importance of peacebuilding operations in recent decades, and the creation of specific organs within the UN to deal with peacebuilding issues, the analytical exercise herein proposed is fundamental for a more structured peacebuilding practice within the UN.

Keywords: Peacebuilding. Peace operations. United Nations 


\section{Referências}

BELLAMY, Alex J.; WILLIAMS Paul; GRIFFIN, Stuart. Understanding Peacekeeping. Cambridge: Polity Press, 2004.

BOUTROS-GHALI, Boutros. An agenda for peace: preventive diplomacy, peacemaking and peace-keeping. n. 17 jun. 1992. Nova Iorque. Disponível em: <http://www.un.org/Docs/SG/agpeace.html>. Acesso em: 12 nov. 2008.

BURGESS, Stephen F. The United Nations under Boutros Boutros-Ghali, 19921997. Lanham: The Scarecrow Press, 2001.

BUZAN, Barry. People, states and fear: an agenda for international security studies in the post-cold war era. Nova Iorque: Harvester Whaetsheaf, 1991.

CALL, Charles T; COOK, Susan. On democratization and peacebuilding. Global Governance. Boulder, Colorado, EUA: Lynne Rienner Publishers, v. 9, n. 2, p. 233 246, 2003.

CARR, Edward H. Vinte anos de crise, 1919-1939: uma introdução ao estudo das relações internacionais. Brasília; São Paulo: UnB; IOESP IPRI, 2001.

DAVID, Charles-Philippe. Does peacebuilding build peace?, In: Ho-Won, Jeong (Ed.) Approaches to peacebuilding. Basingstoke: Palgrave, 2002. p. 18-58.

DIEHL, Paul F. Peace operations. Cambridge: Polity Press, 2008.

DUNN, David J. The first fifty years of peace research: a Survey and Interpretation. Aldershot, Inglaterra: Ashgate, 2005.

DURCH, William J. (Ed.). The Evolution of UN Peacekeeping: case studies and comparative analysis. Nova Iorque: St. Martin's Press, 1993a.

DURCH, William J. The UN Operation in the Congo: 1960-1964, In: DURCH, William J. (Ed.) The evolution of UN peacekeeping: case studies and comparative analysis. Nova Iorque: St. Martin’s Press, 1993. p. 315-352b

EVANS, Gareth. The responsibility to protect: ending mass atrocity crimes once and for all. Washington: Brookings Institution Press, 2008.

FONTOURA, Paulo Roberto Tarrisse da. O Brasil e as operações de manutenção da paz das Nações Unidas. Brasília: FUNAG, 2006. 
FONTOURA, Paulo Roberto Tarrisse da. Brasil: 60 Anos de operações de paz. Rio de Janeiro: Departamento do Patrimônio Histórico e de Documentação da Marinha do Brasil, 2009.

GALTUNG, Johan. Violence, peace and peace research. Journal of Peace Research. Oslo, v. 6, n. 3, p. 167-191, 1969.

GALTUNG, Johan. Three approaches to peace: peacekeeping, peacemaking, and peacebuilding. In: GALTUNG, Johan (Ed.). Peace, war and defence: essays in peace research. Copenhague: Christian Ejlers, 1976. p. 282-304

GALTUNG, Johan. Social cosmology and the concept of peace. Journal of Peace Research, v. 18, n. 2, p. 183-199, 1981.

GALTUNG, Johan. Peace by peaceful means: peace and conflict, development and civilization. Londres: Prio and Sage Publications, 1996.

GHALI, Mona. United Nations Truce Supervision Organization: 1948-Present. In: DURCH, William J. (Ed.). The evolution of UN peacekeeping: case studies and comparative analysis. Nova Iorque: St. Martin’s Press, 1993. p. 84-103.

HELD, David; et.al. Global transformations: politics, economics and culture. Stanford: Stanford University Press, 1999.

HOMER-DIXON, Thomas F. On the Threshold: environmental changes as causes of acute conflict. International Security, v. 16, n 2, p. 76-116, 1991.

JACKSON, Robert. Quasi-States: sovereignty, international relations and the third world. Cambridge: Cambridge University Press, 1990.

JAKOBSEN, Peter Viggo. The transformation of united nations peace operations in the 1990: adding globalization to the conventional 'end of the cold war explanation. Cooperation and Conflict: international studies association, Oslo, v. 37, n. 3, p. 267282, 2002.

JAMES, Alan. The politics of peace-keeping. Londres: Chatto and Windus, 1969.

KALDOR, Mary. New and old Wars: organized violence in a global era. Stanford: Stanford University Press, 1999.

MIALL, Hugh; RAMSBOTHAM, Oliver; WOODHOUSE, Tom. Contemporary conflict resolution. Cambridge: Polity Press, 1999. 
MORGENTHAU, Hans. A Política entre as nações: a luta pelo poder e pela paz. São Paulo: IOESP; Brasília: UnB; 2003.

PARIS, Roland. At war's end: building peace after civil conflict. Nova Iorque: Cambridge University Press, 2004.

PARIS, Roland; SISK, Timothy D. (Ed.). The dilemmas of statebuilding: confronting the contradictions of postwar peace operations. Abingdon: Routledge, 2009.

PROGRAMA DAS NAÇÕES UNIDAS PARA O DESENVOLVIMENTO (PNUD). Human Development Report 1994. Oxford: Oxford University Press, 1994.

PUGH, Michael. Peace-building as developmentalism: concepts from disaster research. Contemporary Security Policy, Reino Unido, v. 16, n. 3, p. 320-346, 1995.

PUREZA, José Manuel. Para que servem os estudos para a paz? Paper apresentando no Congresso Caminhos de futuro: novos mapas para as Ciências Sociais. Coimbra: Centro de Estudos Sociais, 2008.

PUREZA, José Manuel et al. Peacebuilding and failed states: some theoretical notes, 2006, Centro de Estudos Sociais, Universidade de Coimbra. Disponível em: <http://www.ces.uc.pt/publicacoes/oficina/256/256.pdf>. Acesso em: 13 out. 2008.

RAMSBOTHAM, Oliver; WOODHOUSE, Tom; MIALL, Hugh. Contemporary conflict resolution. Cambridge: Polity Press, 2005.

RATNER, Steven. The new UN peacekeeping: building peace in lands of conflict after the cold war. Nova Iorque: St. Martin's Press, 1995.

ROTBERG, Robert I. The new nature of Nation-State failure. The Washington Quarterly, v. 25, n. 3, p. 85-96, 2002.

SCHMID, Herman. Peace research and politics. Journal of Peace Research. Oslo, v. 5, n. 3, p. 217-232, 1968.

SCHNABEL, Albrecht; EHRHART, Hans-Georg. Post-conflict societies and the military: challenges and problems of security sector reform. In: SCHNABEL, Albrecht; EHRHART, Hans-Georg (Ed.) Security sector: reform and post-conflict peacebuilding. Tóquio: United Nations University Press, 2005. p. 1-16.

TERRIFF, Terry et.al. Security studies today. Cambridge: Polity Press, 1999. 
THANT, Myint-U; SCOTT, Amy Scott. The UN Secretariat: a brief history (19452006). Nova Iorque: International Peace Academy, 2007.

UNITED NATIONS. Charter of the United Nations. Nova Iorque: Departamento de Informação das Nações Unidas, 1945. Disponivel em: <http://www.un.org/en/ documents/charter/] >. Acesso em: 17 ago. 2009.

UNITED NATIONS GENERAL ASSEMBLY (AGNU). Letter Dated 3 October 1990 from the Minister for Foreign Affairs of the Union of Soviet Socialist Republics and the Secretary of State of the United Nations of America Addressed to the SecretaryGeneral. A/45/598 (S/21854). Nova Iorque: Assembléia Geral das Nações Unidas, 1990.

VAN CREVELD, Martin. The transformation of war. Nova Iorque: The Free Press, 1991.

WALLENSTEEN, Peter. Peace research: achievements and challenges. Londres: Westview Press, 1988.

WALLENSTEEN, Peter; AXELL, Karin. Major Armed Conflicts. In: STOCKHOLM INTERNATIONAL PEACE RESEARCH INSTITUTE (SIPRI). Yearbook 1994. Oxford: Oxford University Press, p. 81-85, 1994.

WALTZ, Kenneth N. Theory of international politics. Nova Iorque: Mcgraw-Hill Book Co, 1979.

WEISS, Thomas G. The Illusion of UN security council reform. The Washington Quarterly, v.. 26, n. 4, p. 147-161, 2003.

WIBERG, Håkan. Investigação para a paz: passado, presente e futuro. Coimbra. Revista Crítica de Ciências Sociais, v. 71, p. 21-42, 2005.

ZARTMAN, William (Ed.). Collapsed states: the disintegration and restoration of legitimate authority. Londres; Boulder: Lynne Rienner, 1995. 